\title{
Dioxygenases as Targets of Metals, Hypoxia and Oxidative Stress during Carcinogenesis
}

\section{Max Costa *}

Department of Environmental Medicine, New York University School of Medicine NY, NY 10016, USA

In 2006 the first histone demethylase dioxygenase was cloned [1,2] which provided insight as to the mechanisms by which metals; hypoxia and oxidative stress could influence epigenetic programs in cells. In the same year oxidative histone demethylase activity was also discovered in cell extracts and found to be inhibited by nickel ions [3]. Prior to these studies, methylation of histone lysines was thought to be irreversible, particularly the trimethylation of lysines, since H3K4 mono- and dimethylation was found to be reversed by the lysine oxidase enzymes (LSD1, LSD 2, etc.). Later studies demonstrated how nickel ions inhibited the dioxygenase enzymes by displacement of Fe from the active site, given a 3-fold higher affinity compared to that of Fe [4-7]. Recent work on a new class of dioxygenases, the Tet proteins, has given insight into a mechanism of active DNA demethylation [8,9]. The Tet protein, as well as all other dioxygenases will be inhibited by $\mathrm{Ni}$ and $\mathrm{Co}$, hypoxia and oxidative stress resulting, in the case of the Tet protein, in increases in 5-methylcytosine in DNA. Oxidative stress causes a loss of reduced ascrobate, which is required for the dioxygenase to reduce $\mathrm{Fe}^{+3}$ back to $\mathrm{Fe}^{+2}$ and regenerate the active enzyme after molecular oxygen is split during enzyme catalysis. In the case of the proline hydroxylases that hydroxylate hypoxia inducible factor (HIF), their inhibition by metals, hypoxia and oxidative stress greatly stabilizes and increases HIF protein levels which turns off the Krebs cycles genes, turns on glycolytic genes and also causes other significant metabolic changes in the cell. These metabolic changes, which include increased glucose transport and production of VEGF, along with the predominant use of glucose via glycolysis, are reminiscent of the changes that occur in a cancer cell. In the case of the histone demethylases that are dioxygenases as well as the Tet protein, the entire epigenetic program of the cell can be altered temporarily if these enzymes are inhibited. With time, this can result in the selection of a cell type that has malignant properties if the changes in the epigenetic program persist during selection. This may be a mechanism by which $\mathrm{Ni}$ ions, the ultimate carcinogen of nickel compounds, causes cancer, since it is a very potent and broad acting carcinogen that is not toxic or mutagenic, allowing cells to survive and proliferate with altered epigenetic programs. Nickel also stabilizes HIF providing a metabolic profile that is a hallmark of cancer (vide supra).

Oxidative stress is thought to be very important in carcinogenesis, but many of the model systems that we use to study the carcinogenic processes utilize tissue culture. This is where there is a perfect storm for oxidative stress since most cells in culture are grown at $21 \%$ oxygen which is not physiological for many cell types (liver, skin, etc.). To illustrate how non-physiological this system can be, consider why ascorbate is not added to tissue culture media. In the past, I had always wondered why tissue culture media did not include ascorbic acid. The little ascorbic acid that is present in tissue culture media (about $50 \mathrm{uM}$ ) comes from fetal bovine serum. However humans have 1-2 $\mathrm{mM}$ ascorbate present in our cells in vivo, which we obtain exclusively from our diet (rats and mice make their own, which may be a reason that sometimes they are not good models for humans). Thus in tissue culture systems the dioxygenases are very susceptible to oxidative stress and there may be above-normal levels of oxygen radicals in cells grown at $21 \%$ oxygen. However, if $1 \mathrm{mM}$ ascorbate is added to primary cell cultures for longer than a few days to a week, they undergo senescence while immortal cell lines die by apoptosis. Under the $21 \%$ oxygen tension, the ascorbate becomes a pro-oxidant and induces very high levels of oxidative stress causing senescence or apoptosis. Some investigators are aware of these problems, but many are not. The alternatives are to create your own oxygen tension in the $\mathrm{CO}_{2}$ incubator, which can be expensive if a pressurized gas is used; but becomes very economical if run-off $\mathrm{N}_{2}$ form liquid nitrogen is used to generate the atmosphere in the incubator.

Thus research on oxidative stress and in particular with regard to ascorbic acid (the dioxygenases are the only enzymes in humans that use ascorbate and the only reason it is essential) targets the dioxygenase enzyme family initially; but the pro-oxidant effect of ascorbate in the presence of $21 \%$ oxygen produces an abundance of oxygen radicals that induce genes and enzymes that terminate the growth and survival of the cell. Although research in this area is not sufficient, it is likely that all cells grown at $4-5 \%$ oxygen rather than at $21 \%$ will be more similar to the cells in vivo and thus make tissue culture a more relevant model for experimentation. Cells will be healthier, also grow faster and probably, in the case of non-immortalized cells, last for more passages. Unfortunately, immortalized cells which have been grown for many passages for decades may not resemble the cell of origin. This is another area of concern and must be considered in the interpretation of experimental data.

\section{References}

1. Chen Z, Zang J, Whetstine J, Hong X, Davrazou F, et al. (2006) Structura insights into histone demethylation by JMJD2 family members. Cell 125: 691702

2. Whetstine JR, Nottke A, Lan F, Huarte M, Smolikov S, et al. (2006) Reversal of histone lysine trimethylation by the JMJD2 family of histone demethylases. Cell 125: 467-481.

3. Chen H, Ke Q, Kluz T, Yan Y, Costa M (2006) Nickel ions increase histone $\mathrm{H} 3$ lysine 9 dimethylation and induce transgene silencing. Mol Cell Biol 26: 3728-3737.

4. Chen H, Giri NC, Zhang R, Yamane K, Zhang Y, et al. (2010) Nickel ions inhibit histone demethylase JMJD1A and DNA repair enzyme ABH2 by replacing the ferrous iron in the catalytic centers. J Biol Chem 285: 7374-7383.

5. Chen H, Kluz T, Zhang R, Costa M (2010) Hypoxia and nickel inhibit histone demethylase JMJD1A and repress Spry2 expression in human bronchial epithelial BEAS-2B cells. Carcinogenesis 31: 2136-2144.

*Corresponding author: Max Costa, Department of Environmental Medicine, New York University School of Medicine NY, NY 10016, USA, Tel: 845-731-3515; Fax: 845351-2118; E-mail: max.costa@nyumc.org

Received July 10, 2013; Accepted July 11, 2013; Published July 15, 2013

Citation: Costa M (2013) Dioxygenases as Targets of Metals, Hypoxia and Oxidative Stress during Carcinogenesis. J Mol Genet Med 7: 070. doi:10.4172/17470862.1000070

Copyright: (C) 2013 Costa M. This is an open-access article distributed under the terms of the Creative Commons Attribution License, which permits unrestricted use, distribution, and reproduction in any medium, provided the original author and source are credited 
Citation: Costa M (2013) Dioxygenases as Targets of Metals, Hypoxia and Oxidative Stress during Carcinogenesis. J Mol Genet Med 7: 060. doi:10.4172/1747-0862.1000070

Page 2 of 2

6. Davidson TL, Chen H, Di Toro DM, D'Angelo G, Costa M (2006) Soluble nickel inhibits HIF-prolyl-hydroxylases creating persistent hypoxic signaling in A549 cells. Mol Carcinog 45: 479-489.

7. Giri NC, Passantino L, Sun H, Zoroddu MA, Costa M, et al. (2013) Structural Investigations of the Nickel-Induced Inhibition of Truncated Constructs of the JMJD2 Family of Histone Demethylases Using X-ray Absorption Spectroscopy. Biochemistry 52: 4168-4183.
8. Ito S, D'Alessio AC, Taranova OV, Hong K, Sowers LC, et al.(2010) Role of Tet proteins in $5 \mathrm{mC}$ to $5 \mathrm{hmC}$ conversion, ES-cell self-renewal and inner cell mass specification. Nature 466: 1129-1133.

9. Tahiliani M, Koh KP, Shen Y, Pastor WA, Bandukwala H, et al. (2009) Conversion of 5-methylcytosine to 5-hydroxymethylcytosine in mammalian DNA by MLL partner TET1. Science 324: 930-935. 